\title{
A new beetle species from the Russian Far East (Coleoptera: Cucujoidea: Erotylidae)
}

\author{
Новый виА жкуков семейства Erotylidae \\ с Аальнего Востока России: (Coleoptera: Cucujoidea)
}

\author{
G.Yu. Lyubarsky \\ Г.Ю. Аюбарский
}

\begin{abstract}
Zoological Museum of Moscow State University, Bol'shaya Nikitskaya 6, Moscow 125009, Russia. E-mail:
Зоологический музей Московского государственного университета им. М.В.Ломоносова. Большая Никитская 6, Москва 125009, Россия.
\end{abstract}

KEY WORDS: Coleoptera, taxonomy, new species, Erotylidae, Cryptophilini, Cryptophilus, Far East, China, Hubei. КЛЮЧЕВЫЕ СЛОВА: Coleoptera, таксономия, новый вид, Erotylidae, Cryptophilini, Cryptophilus, Дальний Восток, Китай, Хубей.

ABSTRACT. New species of Cryptophilus Reitter, 1874 is described from the Far East of Russia and China.

РЕЗЮМЕ. Новый вид Cryptophilus Reitter, 1874 описан с Дальнего Востока России и Китая.

\section{Introduction}

This publication is based on the material collected by S.A. Kurbatov in the Russian Far East and China. The fauna of this regions is little known. This material contains some rare species of Cryptophagidae (Cryptophagus decoratus Reitter, 1874, C. fusciclavis Bruce, 1943, C. klapperichi Bruce, 1943, C. latangulus Reitter, 1889, C.pseudoschmidti Woodroffe, 1970, C. zonatus Lyubarsky, 1995, Atomaria convexiuscula Reitter, 1888, A. flava Johnson, 1968, A. fuscipes Gyllenhal, 1808, A. plicatoides Johnson, 1970, A. punctithorax Reitter, 1888) and new species of the genus Cryptophilus Reitter, 1874.

\section{Taxonomic part}

Family Erotylidae Latreille, 1802

Genus Cryptophilus Reitter, 1874

The genus belongs to the family Erotylidae [Leschen, 2003]. Cryptophilus are sapro/mycetophagous [Leschen \& Buckley, 2007], inhabits decaying plant material, stored grain. Some species of related genera either live on cycad pollen, being sometimes cycad pollinators [Chaves \& Genaro, 2005], or being phoretic on cricetine rodents [Leschen \& Ashe, 1999] and endoparasitic of lepidoptera pupae [Leschen, 1997]. Cryptophilus is usually found in fallen leaves and hay.

Nine species of the genus are distributed in Palaearctic [Wegrzynowicz, 2007]:
Cryptophilus cryptophagoides Grouvelle, 1916 (Taiwan, Japan);

Cryptophilus hiranoi Sasaji, 1984 (Japan);

Cryptophilus integer Heer, 1841 (cosmopolitan);

Cryptophilus minimus Grouvelle, 1914 (Taiwan);

Cryptophilus mirus Grouvelle, 1914 (Taiwan);

Cryptophilus obliteratus Reitter, 1874 (W Europe, Russian Far East, China, Japan);

Cryptophilus propinguus Reitter, 1874 (Japan, Taiwan); Cryptophilus quadrisignatus Motschulsky, 1860 (Russian Far East, China: Shaanxi, Japan);

Cryptophilus reitteri Iablokoff-Khnzorian, 1975 (Japan).

\section{Cryptophilus kurbatovi sp.n.}

Fig. 1

MATERIAL. Holotype: + , Russia, Far East, Lazo village, 13.05.2009, leg. S.A. Kurbatov. Paratypes: 2 우, China, E. Hubei, Shennongjia Nat.Res., env. Macheng, Longsheng, $500 \mathrm{~m}$, letter, 29.05.1995, leg. S.A. Kurbatov.

DESCRIPTION. Elongate oblong oval, 1.9-2.0 times as long as wide (Fig. 1), dorsum weakly convex, dorsal pubescence dense and yellowish white. Head, pronotum, scutellum and elytra light-brown, and antennae, mouth parts and legs reddish brown. Underside brown. Body length: 1.9-2.0 mm, width $1 \mathrm{~mm}$.

Head large, width including eyes two-thirds as much as pronotal width; eyes relatuvely small, maximum diameter about 0.5 of interocular distance. Frons weakly convex, strongly and coarsely punctate, distance between punctures much narrower than the diameter of puncture Antennae nearly as long as pronotal width, relatively stout. Basal segment cylindrical, a little longer than thick; second somewhat shorter and much narrower than basal; third distinctly longer than second; fourth nearly as long as second; eighth nearly as long as wide; ninth distinctly wider than long, distinctly thickening apically; tenth nearly as ninth in size and shape; terminal segment pyriform, as long as thick with pointed narrow tip.

Pronotum transverse oblong, $0.64-0.67$ as long as wide, and $0.39-0.42$ times as long as length of elytra. Lateral sides weakly arcuately narrowing anteriorly, widest near middle of 


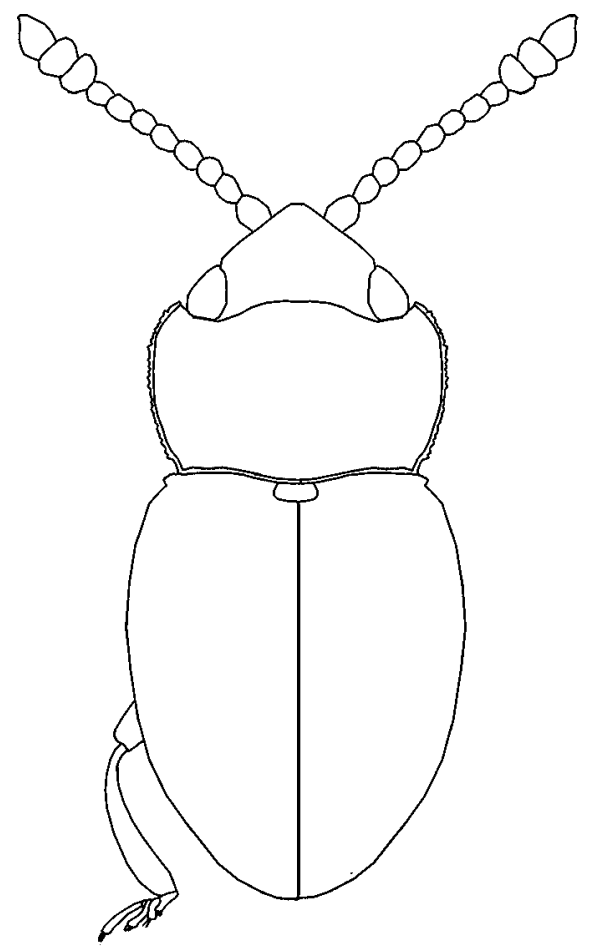

Fig. 1. General view of Cryptophilus kurbatovi sp.n.

Рис. 1. Cryptophilus kurbatovi sp.n., внешний вид.

pronotal length. Apical corners widely produced anteriorly and rectangulate with a rounded tip; anterior margin rather strongly bisinuate; basal corners indistinctly and obtusely angulate, not produced laterally; basal margin gently but distinctly arcuate. Pronotal disc extremely closely and relatively strongly punctate. Punctation of frons and pronotum very clearly impressed. Lateral areas of pronotum rather widely depressed along lateral sides which are narrowly marginated; punctures on lateral depressions very large. Scutellum transverse oblong oval and finely punctate.

Elytra elongate, 1.24-1.33 as long as combined width, widest near middle of this length, humerus with a denticle distance between both denticles just as much as pronotal maximum width. Elytral surface strongly and moderately punctate, distance between punctures much narrower than the diameter of puncture, interspace between punctures somewhat convex and sometimes transversely rugose, especially at lateral areas. Elytral outer margin marginated, the margination wider and deeper at anterior part. Elytral pubescence slightly elevat- ed, hairs long, length of hair more than length of claw.

Anterior coxal cavities closed behind. Prosternal process narrow near the base, posterior three-fourths strongly divergent apically, widest part about twice as much as narrowest part; apex of the process deeply, triangularly excavate. Punctation of metasternum rather fine at medium part and very strong at lateral parts. Legs relatively stout. All tarsi with bilobed $1^{\text {st }}, 2^{\text {th }}$, and $3^{\text {th }}$ segments. $1^{\text {st }}$ segment of posterior tarsi weakly elongated, little than 3 times as long as width. $4^{\text {th }}$ segment very little, indistinctly visible. Tibia without thorns and spikes. Membranous wings fully developed.

DISTRIBUTION. Russian Far East, China (Hubei).

REMARKS. The unique proportions of body, elytral shape and structure of anterior pronotal corners make this new species being quite different from other congeners. C. kurbatovi sp.n. is compared with C. quadrimaculatus and $C$. integer: C. kurbatovi: elytra $1.24-1.33$ as long as combined width; C. quadrimaculatus: elytra $1.5-1.68$ as long as combined width; $C$. integer: elytra $1.5-1.76$ as long as combined width. C. kurbatovi: humerus of elytra with a strong denticle; C. quadrimaculatus: humerus of elytra with a strong denticle; C. integer: humerus with a weak denticle. C. kurbatovi: anterior margin of pronotum bisinuate; $C$. integer: anterior margin of pronotum without sinuate. $C$. integer: $1^{\text {st }}$ segment of posterior tarsi strongly elongate, more than 3 times as long as width.

ETHYMOLOGY. Named in honour of S.A. Kurbatov.

\section{References}

Chaves R. \& Genaro J.A. 2005. A new species of Pharaxonotha (Coleoptera: Erotylidae), probable pollinator of the endangered Cuban cycad, Microcycas calocoma // Insecta Mundi. Vol.19. No.3. P.143-150

Leschen R.A.B. 1997. The Empocryptus-group (Languriidae: Toraminae) and a new genus associated with a lepidopteran cocoon // Coleopt. Bull. Vol.51. P.303-318.

Leschen R.A.B. 2003. Erotylidae (Insecta: Coleoptera: Cucujoidea): phylogeny and review // Fauna of New Zealand. Vol.47. 108 pp.

Leschen R.A.B. \& Ashe J.S. 1999. New species, phylogenetic placement, and mammal associations of Loberopsyllus (Languriidae: Xenoscelinae) // G.W. Byers, R.H. Hagen, and R.W. Brooks (Eds.). Entomological contributions in Memory of Byron Alexander. University of Kansas Natural History Museum Special Publication. Vol.24. P.171-177.

Leschen R.A. \& Buckley T.R. 2007. Multistate characters and diet shifts: evolution of Erotylidae (Coleoptera) // Syst.Biol. Vol.56. No.1. P.97-112.

Wegrzynowicz P. 2007. Family Erotylidae // I. Lobl, A. Smetana (eds.). Catalogue of Palaearctic Coleoptera. Apollo Books. Stenstrup. Vol.4. P.531-546. 